North American Journal of Aquaculture 1999, vol.61, no.3, p.258-262.

http://afs.allenpress.com/perlserv/?request=get-archive

http://afs.allenpress.com/archive/1548-8454/61/3/pdf/i1548-8454-61-3-258.pdf

DOI: 10.1577/1548-8454(1999)061<0258:COMAYP>2.0.CO;2

Online ISSN: 1548-8454

Print ISSN: 1522-2055

(C) American Fisheries Society 


\title{
Cryopreservation of Muskellunge and Yellow Perch Semen
}

\author{
Jan Glogowski And Andrzej Ciereszko \\ The Ohio State University, School of Natural Resources, \\ 210 Kottman Hall, Columbus, Ohio 43210, USA and \\ Department of Molecular Andrology, Institute of Animal Reproduction and Food Research, \\ Polish Academy of Sciences, 10-718 Olsztyn, Poland \\ KONRAD DABROWSKI* \\ The Ohio State University, School of Natural Resources, \\ 210 Kottman Hall, Columbus, Ohio 43210, USA
}

\begin{abstract}
Effect of four extenders on the success of cryopreservation of the semen of muskellunge Esox masquinongy and yellow perch Perca flavescens was tested These extenders consisted of $0.45 \mathrm{M}$ sucrose and were supplemented with either (1) $15 \%$ dimethyl sulfoxide (DMSO), (2) 15\% DMSO and 10\% hen's egg yolk, (3) $15 \%$ dimethylacetamide (DMA), or (4) 15\% DMA and $10 \%$ egg yolk. The use of extender with DMA alone yielded only about 7\% muskellunge sperm fertilizing ability after cryopreservation. Supplementation of this extender with egg yolk produced a fertilization rate (36.6\% of the control where fresh sperm was used) not significantly different from rates obtained with extenders containing DMSO. No significant differences were found among particular pools (consisting of semen from three different males per pool) of muskellunge semen used in this experiment. Fertilization rates of cryopreserved yellow perch semen (range, $69.6 \%$ to $77.3 \%$ ) were not significantly different among all extenders tested. Cryopreservation success differed significantly between milt samples from individual yellow perch males. Yellow perch eggs could be stored up to $77 \mathrm{~min}$ at $10^{\circ} \mathrm{C}$ (fertilization success ranged from $57.2 \%$ to $64.8 \%$ ). Our results provided $25-35 \%$ improvement of cryopreservation technology for yellow perch semen (measured as fertilization rate) and new data for cryoprotectant use in muskellunge. We were also able to prolong in vitro viability of yellow perch eggs during storage compared with earlier attempts.
\end{abstract}

Importance of cryopreservation for long-term storage of spermatozoa is now widely recognized (Cloud et al. 1990). Cryopreservation procedures for fish milt include dilution of milt in an extender, a short equilibration period (for some species), freezing of diluted milt, storage in liquid nitrogen, and thawing in appropriate solutions. However, it appears that these protocols must be optimized for each fish species. The most critical factors that need be optimized are the composition of the extender, equilibration time, rate of freezing and

* Corresponding author: dabrowski.1@osu.edu

Received June 10, 1998; accepted February 4, 1999 thawing, and composition of thawing solutions. The quality of the semen is also critical for successful cryopreservation (Billard 1990, 1992). Milt samples that are contaminated with urine or that have been stored too long before freezing can decrease cryopreservation success (Stoss 1983; Rana 1995).

Despite optimization efforts, the cryopreservation process usually produces damage to large numbers of spermatozoa. Therefore, only a small fraction of spermatozoa are viable after freezingthawing. For this reason, more cryopreserved milt than fresh milt (up to 10 times) is needed to fertilize the same number of oocytes (Billard 1992). Even such an increased number of cryopreserved spermatozoa does not always provide the same fertilization success as fresh milt. This low fertilizing success of cryopreserved semen is not economically feasible for hatchery production because of the high costs of sperm storage and low efficiency. Therefore, efforts must be directed to achieving fertilization rates with cryopreserved semen similar to those obtained with fresh semen.

Ciereszko et al. (1993) and Lin et al. (1996) reported the successful cryopreservation of the semen of yellow perch Perca flavescens and muskellunge Esox masquinongy. However, for both species, the fertilization rate of cryopreserved semen was only about $40 \%$ of fresh semen. We also observed a decrease in quality of yellow perch eggs after 30-min storage at room temperature $(\mathrm{Ci}-$ ereszko et al. 1993). This seriously limits the use of a single batch of eggs for testing larger numbers of individual milt samples.

In this study, our objectives were to evaluate the effectiveness of simple extenders consisting of sucrose supplemented with dimethyl sulfoxide, dimethylacetamide, or hen's egg yolk to improve the cryopreservation success of muskellunge and yellow perch milt and to improve short-term storeability of yellow perch eggs. 


\section{Methods}

Muskellunge were caught by trap nets in Clear Fork Reservoir, Ohio. Fish were stripped of milt or eggs as described in Lin et al. (1996). Muskellunge semen was collected from 12 males in May. Four semen pools were formed, each consisting of three different milt samples. Yellow perch were cultured using artificial diets at the Piketon Research and Extension Center, Piketon, Ohio (Ciereszko et al. 1993). Also in May, yellow perch semen was obtained from five males but was not pooled before cryopreservation. Only samples with sperm motility of at least $90 \%$ (estimated under light microscope) were selected for cryopreservation. Milt was diluted (100-fold) and activiated in $0.5 \% \mathrm{NaCl}$ for motility estimation. Average sperm concentrations (mean $\pm \mathrm{SE}$, estimated as described by Ciereszko and Dabrowski (1993), were $17.9 \pm 2.0 \times 10^{9}$ and $48.5 \pm 1.6 \times 10^{9}$ spermatozoa for muskellunge and yellow perch, respectively. Eggs were collected from one female of each species at the same time as semen collection. Quality of short-term storage of yellow perch eggs was evaluated at $10^{\circ} \mathrm{C}$ and $12^{\circ} \mathrm{C}$. For this purpose, eggs (in a layer $0.5 \mathrm{~cm}$ deep) were kept in a plastic beaker in a water bath. The plastic beaker was loosely covered with a plastic lid. Fertilizing ability of eggs was tested after 11 and 72 min at $12^{\circ} \mathrm{C}$, and after $23,32,40,56,68$, and 77 min of storage at $10^{\circ} \mathrm{C}$.

The following extenders were used: (1) DMSO (15\% dimethyl sulfoxide), (2) DMSO-yolk (15\% DMSO and $10 \%$ egg yolk), (3) DMA (15\% dimethylacetamide), and (4) DMA-yolk (15\% DMA and $10 \%$ egg yolk). All extenders contained 0.45 M sucrose. The extender vehicle was double distilled water. Semen was cryopreserved on dry ice according to methods previously described (Ciereszko et al. 1993; Ciereszko and Dabrowski 1996; and Lin et al. 1996), but 0.05-mL pellets were formed instead of $0.1-\mathrm{mL}$ pellets. After $5 \mathrm{~min}$ on dry ice, the pellets were transferred to liquid nitrogen. Samples were frozen in the field (muskellunge) or laboratory (yellow perch) within $1 \mathrm{~h}$ after collection of semen. Frozen milt of muskellunge and yellow perch were stored in liquid nitrogen for $4 \mathrm{~h}$ and 5-12 d, respectively.

Four pellets from each pooled muskellunge semen sample were thawed at $30^{\circ} \mathrm{C}$ in $5 \mathrm{~mL}$ of 30 $\mathrm{mM}$ tris- $\mathrm{HCl}$ buffer, $\mathrm{pH} 8.0$, containing $75 \mathrm{mM}$ $\mathrm{NaCl}$ (activation medium); the solution was then poured over $4 \mathrm{~g}$ of eggs (approximately 400 eggs). Sperm: egg ratio was about $2.5 \times 10^{6}: 1$. Fresh semen (stored $6 \mathrm{~h}$ on ice) was used as a control for the same pooled samples. Embryos were incubated in a miniature Weiss apparatus as described by Bardega and Luczynski (1990). The percentage of eyed and hatched embryos was determined at 4 and $8 \mathrm{~d}$, respectively.

Pellets (1-2) from each male yellow perch were thawed in $5 \mathrm{~mL}$ of $0.5 \% \mathrm{NaCl}$ at $21^{\circ} \mathrm{C}$. About 3 $\times 10^{6}$ spermatozoa per egg were employed during fertilization. Fresh semen (stored for $1 \mathrm{~h}$ on ice) from three pooled males was used as a control. Eggs were kept in covered plastic trays in a water bath at temperatures between $10^{\circ} \mathrm{C}$ and $12^{\circ} \mathrm{C}$ before fertilization. After fertilization, eggs were incubated in California trays as described by $\mathrm{Ci}$ ereszko et al. (1993). The percentage of eyed embryos was determined after $6 \mathrm{~d}$ and expressed as percentage of controls (pooled fresh semen).

One-way analysis of variance (ANOVA) for repeated measures was used to evaluate cryopreservation success. Fisher's least-significant-difference test was used for posthoc comparison of means. Percentage data were subjected to arcsine transformation; $P<0.05$ was chosen as the test of significance.

\section{Results}

Fertilization rates with fresh sperm were 63.8 $\pm 1.3 \%$ and $61.1 \pm 3.1 \%$ for muskellunge and yellow perch, respectively. The fertilization rate of yellow perch eggs stored at $12^{\circ} \mathrm{C}$ was $91.5 \%$ after $11 \mathrm{~min}$ of storage and $74.5 \%$ after $72 \mathrm{~min}$ of storage. Storage temperature of $10^{\circ} \mathrm{C}$ provided good quality perch eggs for at least $77 \mathrm{~min}$. Fertilization rate of eggs stored at $10^{\circ} \mathrm{C}$ was 61.4 , $57.2,59.3,64.7,64.9$ and $59.2 \%$ after 23, 32, 40, 56,68 and $77 \mathrm{~min}$ of storage, respectively.

Cryopreservation success (38-40\%, expressed as percentage of control, which was $24-25 \%$ actual fertilization) for muskellunge semen was not significantly different when comparing extenders containing DMSO (Figure 1A). The use of DMA alone as an extender provided only about $7 \%$ of sperm fertilizing capacity, whereas supplementation of this extender with egg yolk produced a sperm fertilization rate $(36.6 \%)$ not significantly different from those obtained with extenders containing DMSO. Similar results were obtained when fertilization rate was evaluated at the eyed stage (Figure 1A). We obtained fertilization success expressed as eyed embryos $(69.6-77.3 \%$ of control which was equal to $42.5-47.2 \%$ actual fertilization) for cryopreserved yellow perch milt that was higher than that for muskellunge when using the 

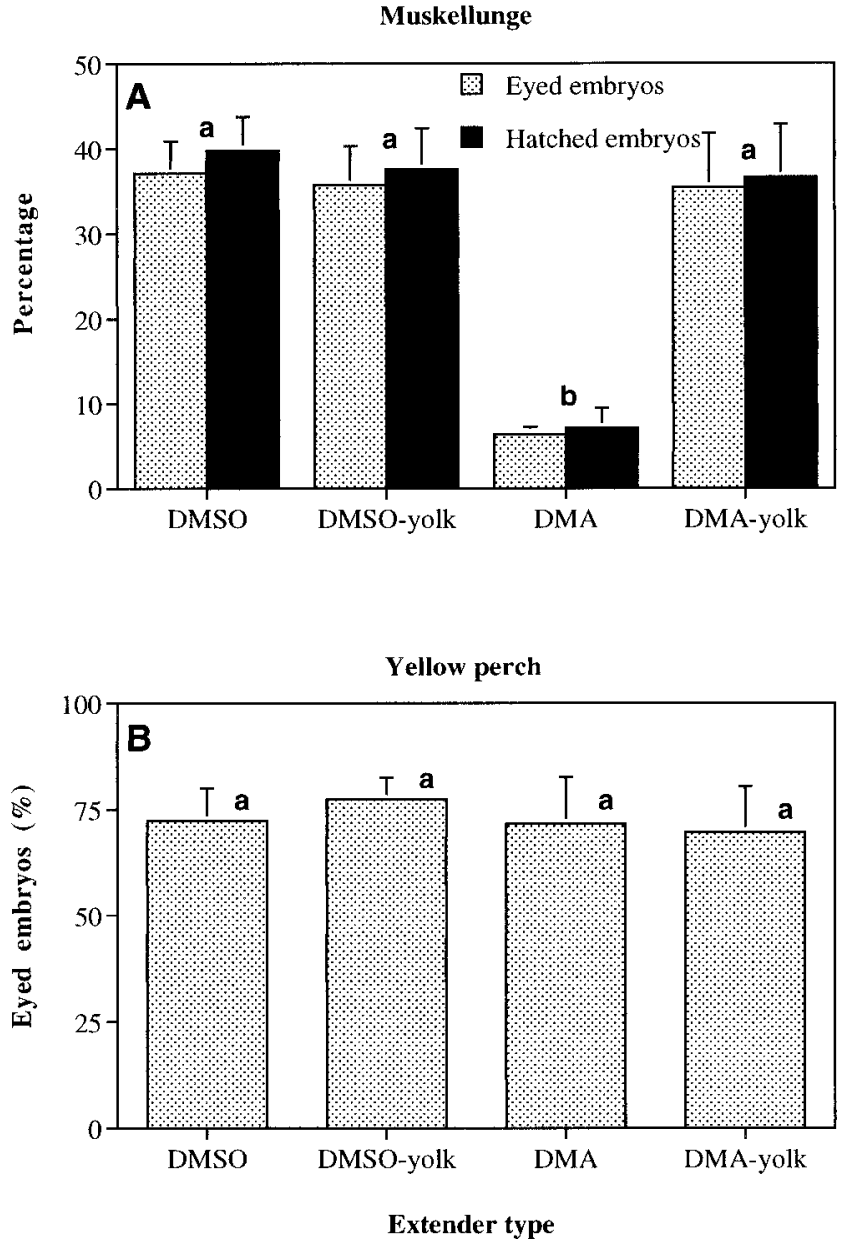

FIGURE 1.-Fertilizing ability expressed as percent of control (mean \pm SE) for (A) muskellunge and (B) and yellow perch spermatozoa cryopreserved with one of four extenders: $0.45 \mathrm{M}$ sucrose supplemented with $15 \%$ dimethyl sulfoxide (DMSO), 15\% DMSO and 10\% hen's egg yolk, 15\% dimethylacetamide (DMA), or 15\% DMA and $10 \%$ egg yolk. Among extender types mean values without a lower case letter in common are significantly different $(P<0.05)$.

same extenders (Figure 1B). Similar cryopreservation success $(65.1-69.2 \%)$ was obtained when using eggs stored at $12^{\circ} \mathrm{C}$ (data not shown). We did not observe a decrease in fertilization rate of yellow perch sperm when DMA extender was used, as was the case for muskellunge semen, and there were no significant differences between extenders.

We did not observe significant differences in fertilizing capacity between four pools of cryopreserved muskellunge milt (Figure 2A). We found that one male yellow perch had semen of significantly lower quality than the other four yellow perch (Figure 2B). Data for individual males (yellow perch) or pools of semen (muskellunge) cryopreserved in four extenders were combined for these calculations.

\section{Discussion}

We found that yellow perch eggs can be stored up to $77 \mathrm{~min}$ at $10^{\circ} \mathrm{C}$ before fertilization. This observation is important for performing fertilization trials when many semen samples need to be tested on one group of eggs. Yellow perch eggs are more prone to deterioration during storage than muskellunge eggs. For example, $8 \mathrm{~h}$ of muskellunge egg storage at $10-13^{\circ} \mathrm{C}$ did not affect fertility of eggs (Lin and Dabrowski 1996).

The effectiveness of all four extenders for cryopreservation of yellow perch semen appeared to 

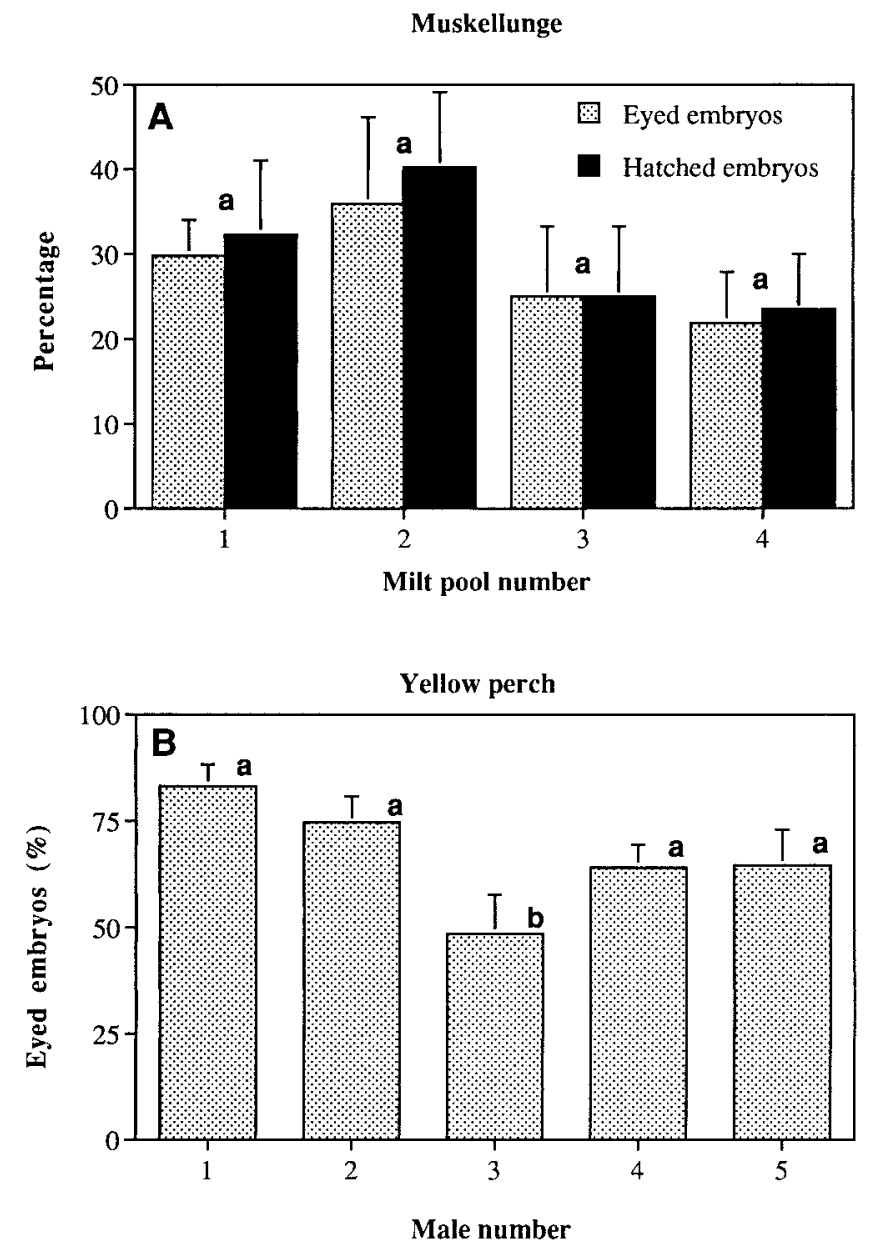

FIGURE 2.-Cryopreservation success measured as mean \pm SE percent fertilization for (A) pools of cryopreseved muskelunge semen and (B) and individual samples of yellow perch semen. Mean values without a lower case letter in common are significantly different $(P<0.05)$.

be similar, and they produced about $70 \%$ fertilization of frozen-thawed semen. This is about a $30 \%$ improvement compared with our earlier results (Ciereszko et al. 1993). Previously, we used an extender consisting of $125 \mathrm{mM}$ sucrose, $6.5 \mathrm{mM}$ glutathione, $100 \mathrm{mM}$ potassium bicarbonate, and $8 \%$ DMSO. Our results indicate that simple extenders consisting of $15 \%$ of either DMSO and DMA and $0.45 \mathrm{M}$ sucrose are more effective for yellow perch. It should be pointed out, that better fertilization rates obtained in our experiments may be also related to lower osmolality of the thawingfertilization solution used $(0.5 \% \mathrm{NaCl}$ instead of the $0.7 \% \mathrm{NaCl}$ used previously). It appeared that DMA, introduced recently for cryopreservation of fish sperm (McNiven et al. 1993), may be successfully used for yellow perch semen as well. The usefulness of DMA for cryopreservation of muskellunge spermatozoa, however, is doubtful because its successful cryoprotection was seen only in the presence of $10 \%$ egg yolk. The DMA appeared to be toxic to muskellunge spermatozoa, and egg yolk was able to counteract this effect. The cryoprotective effect of egg yolk was seen only in this case. We observed no beneficial effect of egg yolk when combined with DMSO or with DMA for yellow perch semen. Recently, Babiak et al. (1998) observed that the presence of egg yolk in extenders decreased fertilization success of the cryopreserved milt of a cyprynid, asp Aspius aspius. These data suggest that cryoprotective effect of egg yolk may be species specific.

In conclusion, our results provide an improvement of cryopreservation technology for yellow 
perch semen and new data for cryoprotectant use in muskellunge. We were also able to prolong yellow perch egg viability compared with earlier attempts. As we discussed previously, because of the availability of yellow perch milt outside of the natural spawning season (Dabrowski et al. 1996), its cryopreservation may offer an attractive tool for the breeding of yellow perch

\section{Acknowledgments}

This study was partly funded by the Ohio Department of Natural Resources (Federal Aid in Sport Fish Restoration, project F-69-P) and the Lake Erie Protection Fund, Toledo, Ohio. Salaries were partly provided by the Ohio Agriculture Research and Development Center, Wooster, Ohio. We thank Patricia Laskowski for commenting on the manuscript.

\section{References}

Babiak, I., J. Glogowski, R. Kujawa, D. Kucharczyk, and A. Mamcarz. 1998. Cryopreservation of sperm from asp Aspius aspius. Progressive Fish-Culturist 60:146-148.

Bardega, R., and M. Luczynski. 1990. Experimental hatchery and larvae rearing unit. Acta Academiae Agriculturae ac Technicae Olstenensis Protectio Aquarum et Piscatoria 18:87-93.

Billard, R. 1990. Artificial insemination in fish. Pages 870-888 in G. E. Lamming, editor. Marshall's physiology of reproduction, volume 2 , reproduction in the male. Churchill Livingstone, New York.

Billard, R. 1992. Reproduction in rainbow trout: sex differentiation, dynamics of gametogenesis, biology and preservation of gametes. Aquaculture 100:263298.

Ciereszko, A., and K. Dabrowski. 1993. Estimation of sperm concentration of rainbow trout, whitefish, and yellow perch using a spectrophotometric technique. Aquaculture 109:367-373.

Ciereszko, A., and K. Dabrowski. 1996. Effect of sucrose-DMSO extender supplemented with pentoxifylline or blood plasma on fertilizing ability of cryopreserved rainbow trout spermatozoa. Progressive Fish-Culturist 58:143-145.

Ciereszko, A., L. Ramseyer, and K. Dabrowski. 1993. Cryopreservation of yellow perch semen. Progressive Fish-Culturist 55:261-264.

Cloud, J. G., W. H. Miller, and M. J. Levanduski. 1990. Cryopreservation of sperm as a means to store salmonid germ plasm and to transfer genes from wild fish to hatchery populations. Progressive FishCulturist 52:51-53.

Dabrowski, K., and six coauthors. 1996. Reproductive physiology of yellow perch (Perca flavescens): environmental and endocrinological cues. Journal of Applied Ichthyology 12:139-148.

Lin, F., A. Ciereszko, and K. Dabrowski. 1996. Sperm production and cryopreservation in muskellunge after carp pituitary extract and human chorionic gonadotropin injection. Progressive Fish-Culturist 58: 32-37.

Lin, F., and K. Dabrowski. 1996. Effects of sperm irradiation and heat shock on induction of gynogenesis in muskellunge (Esox masquinongy). Canadian Journal of Fisheries and Aquatic Sciences 53:20672075.

McNiven, M. A., R. K. Gallant, and G. F. Richardson. 1993. Dimethyl-acetamide as a cryoprotectant for rainbow trout spermatozoa. Theriogenology 40: 943-948.

Rana, K. 1995. Cryopreservation of aquatic gametes and embryos: recent advances and applications. Pages 85-89 in F. W. Goetz and P. Thomas, editors. Proceedings of the 5th international symposium on the reproductive physiology of fish. University of Texas, Austin.

Stoss, J. 1983. Fish gamete preservation and spermatozoan physiology. Pages 305-350 in W. J. Hoar, D. J. Randall, and E. M. Donaldson, editors. Fish physiology, volume 9, part B. Academic Press, Orlando, Florida. 